Preliminary Draft

April 11, 2001

Comments Solicited

\title{
HAS THE GROWTH OF SCIENCE CROWDED OUT OTHER THINGS AT UNIVERSITIES?
}

by

Ronald G. Ehrenberg and Julia Epifantseva*

* Ehrenberg is the Irving M. Ives Professor of Industrial and Labor Relations and Economics at Cornell University, Research Associate at the National Bureau of Economic Research and Director of the Cornell Higher Education Research Institute (CHERI). Epifantseva is a $\mathrm{PhD}$ candidate in economics at Cornell University. We are grateful to Provost Jonathan Cole of Columbia University for granting us access to the Interuniversity Salary Exchange data that we use in the paper and to the Andrew W. Mellon Foundation and other donors for their support of CHERI. The Interuniversity Salary Exchange data were collected from participating institutions under conditions of strict confidentiality and they were provided to us under the same conditions. Hence, we are not permitted to share them with other researchers. 


\section{Introduction}

Scientific research has come to dominate many major American university campuses and this is reflected in the ways that universities are ranked. U.S News \& World Report $s$ ranking of national universities as undergraduate institutions places heavy weight on the volume of external research funding that faculty members at the universities receive. ${ }^{1}$ The 1994 Carnegie Foundation classification of $\mathrm{PhD}$ granting institutions into Research I, Research II, Doctoral I and Doctoral II institutions similarly was heavily based on the institutions' volumes of research funding and institutions strove mightily to increase their funding to receive a higher classification in the next Carnegie revision of their classification scheme. ${ }^{2}$ Concerned that this behavior was causing the institutions to place too much weight on their faculty members' external research funding and not enough weight on the quality of their graduate programs, the foundation collapsed its four PhD categories into two in 2000 and based an institution's new classification solely on the number of PhDs that it produced each year and not on its research volume. ${ }^{3}$

Of course the growth of scientific research, which is driven by the availability of government, corporate and foundation funding, does not derive primarily from the various ranking and classification schemes. The growing importance of science at research universities reflects the major advances being made in science at the turn of the $21^{\text {st }}$ century and the importance of these advances to our society. To take an example, recent advances in decoding the human genome, in advanced materials, and in information sciences lead to promise of major advances in health care treatments in the

${ }^{1}$ U.S. News \& World Report (1999)

${ }^{2}$ Carnegie Foundation for the Advancement of Teaching (1994) 
years ahead. Any university worth its salt wants to be a leader in these fields so that it can attract top faculty, undergraduates and graduate students, as well as increase funding for its programs.

While many faculty members associated with the arts and humanities and the social sciences bemoan what appears to be an ever increasing share of campus resources going to science, there is little hard evidence about whether the growth in science has come at the expense of other fields at universities. In this brief paper, we present an initial approach to this question, using data for a recent 20 -year period from the colleges of arts and sciences at a set of selective private research universities. Specifically, we examine whether the shares of faculty positions and of the faculty salary bill going to science have increased at each of these institutions over the period? Our major finding, which we confess that we did not expect to observe, is that, on balance, the sciences' shares of faculty numbers and faculty salaries in these institutions' colleges of arts and sciences have not systematically increased over the period.

\section{The Data}

From 1978-79 to $1997-98$, the colleges of arts and sciences at leading private research universities took part in an "Interuniversity Salary Exchange Survey" that was housed at Columbia University. ${ }^{4}$ The initial survey included seven of the eight Ivy League institutions, Johns Hopkins, MIT, the University of Rochester, Stanford University and Washington University at St. Louis. Over the years participation in the survey grew to include the eighth Ivy League institution (Dartmouth), Cal. Tech., Chicago, Duke, Emory, Georgetown and Northwestern. So depending upon how far back

\footnotetext{
${ }^{3}$ Julianne Basinger (2000)
} 
one wants to go, one can track the information for between 12 and 19 selective private research universities.

The survey collected data each year from each institution on the number of Arts and Sciences faculty employed by the institution and the distribution of their salaries by rank (assistant, associate and full professor) and three broad fields (arts and humanities, social sciences, and natural sciences). Examples were given of the departments that should be included in each broad field, but the institutions were permitted to indicate differences in where they reported specific disciplines. For example, while most institutions included history within the social sciences, several included it within the humanities. Similarly, while many included psychology within the sciences, others included it in the social sciences.

The institutions that participated in the salary exchange program did so to gain an understanding of how their faculty compensation policies compared, on average to their competitors. This information was useful to them in the setting of subsequent salary policies. The institutions did not discuss, however, what their future policies would be; they only exchanged historical information. Hence the salary exchange program did not violate the Consent decree that the Ivies had entered into with the Department of Justice in the early 1990 s. $^{5}$

\section{Empirical Analyses}

Under the condition that we would keep the data confidential and not associate the name of any specific institutions with findings for it in our work, we were granted access to these data. We restricted our attention to 15 of the institutions that were in the

\footnotetext{
${ }^{4}$ A successor survey conducted by the Consortium on Financing Higher Education (COFHE) began in 1998-99.
} 
sample continuously (missing at most one year) over the entire period. The institutions were ordered randomly and each assigned a number to mask its identity in what follows. For each institution we computed the shares of faculty positions in the arts and humanities, social sciences, and sciences each year, as well as the shares of faculty salary dollars going to each of the three areas in each of the years.

In the first year that each institution was in the sample, the share of faculty positions in the arts and humanities varied across institutions from .09 to $.41 .{ }^{6}$ Similarly, the shares of faculty positions in the social sciences varied between .11 and .34 and the shares of faculty positions in the sciences varied between, .29 and .80 . Some of the differences across colleges in the initial shares in each field reflect differences in institutional priorities and some reflect differences across institutions in the classifications of departments such as history and psychology into the three broad areas. Finally, some reflect the fact that some departments that are normally found in colleges of arts and sciences are found in other colleges at some of the universities. For example, a high proportion of the art and music faculty in some of the institutions are housed in colleges of fine arts or conservatories.

Our concern is not with why the initial shares of faculty in each of the three disciplinary areas varied across institutions but with how the shares for each institution varied over time. To see if there were systematic trends, we first estimated the following three equations for each institution:

(1) $S_{j t}=a_{j}+b_{j} t+{ }_{j t} j=1,2,3$

\footnotetext{
${ }^{5}$ Scott Jaschik (1991)

${ }^{6}$ For most institutions the initial year was 1978-79. However, for several it was 1979-80.
} 
These equations specify that the share of faculty positions, (S) going to each of the three disciplines in a year, is a linear function of a time trend term ( $t$ is set equal to one in the initial year and a random error term. Hence, the signs of the estimates of the coefficients $b_{j}$ will indicate to us whether the share of faculty in field $j$ increased (positive) or decreased (negative) during the period.

Estimates of the coefficient of the time trend term from this model for each institution appear in columns (a) of table 1. The method of estimation used corrected for autocorrelation over time in the error term in each equation. Quite strikingly, one does not find strong evidence from these coefficients that the share of faculty in the sciences at these colleges of arts and sciences has grown relative to the other two fields over time.

The number of colleges in which the humanities' share trend term is negative and statistically significantly different from zero at the .05 level of significance (3) is actually smaller than the number of institutions in which the coefficient is positive and statistically significantly different from zero (4). Similarly, while 5 of the social science share trend coefficients are negative and statistically significant, indicating a decline in the share of faculty positions going to the social sciences, 6 of the trend coefficients are positive and statistically significantly different from zero indicating that the social sciences' share increased at these institutions. Indeed, at only 1 institution was the trend coefficient in the science share equation positive and statistically significant indicating that the share of science faculty grew during the period and this was offset by two institutions having a statistically significant and negative science share trend coefficient.

Of course equation (1) is very simplistic and ignores the fact that the shares of faculty in different disciplines may vary over time as the enrollments in courses in the 
various disciplines changes. If enrollments in science courses, as a share in total enrollments were declining during the period, even having the share of faculty in the sciences remaining constant might indicate that increasingly more weight was being given to hiring science faculty at these universities during the period.

Data on enrollments in courses in the various disciplines are not systematically available to us, however information on the disciplinary distribution of degrees granted by the institution are collected each year as part of the Integrated Postsecondary Education Data System (IPEDS). ${ }^{7}$ Thus for each institution and each year, we are able to compute estimates of the fractions of degrees granted by the college of arts and sciences in each of the three disciplinary areas at both the undergraduate and graduate degree levels.

While for each institution we were careful to assign degrees to the appropriate disciplinary area (e.g. in some cases psychology was classified as a science and in other cases as a social science), these data on the distributions of degrees granted are only rough proxies for the distribution of course enrollments for at least two reasons. First, some degrees, such as biology may be granted in more than one college at a university and we are treating each of these degrees as if it was an arts and science degree. ${ }^{8}$ Second, the demand for faculty teaching resources in a field depends upon the number of students who take courses in the field, not just the number of degrees granted. So, for example, if universities increasingly established foreign language requirements as the period proceeded, the demand for humanities faculty members would increase over the period.

\footnotetext{
${ }^{7}$ These data area available online at the National Science Foundations WEBCASPAR site $(<\mathrm{http}: / /$ caspar.nsf.gov>).
} 
However, we would not capture this by our knowledge of changes in the number of humanities degrees granted by the universities.

Nonetheless, using the data on the field distribution of degrees granted is the best that we can do to control for changes in the demand for faculty for teaching purposes in each field at each institution. We reestimated versions of equations (1) for each field that also included as explanatory variables the fraction of undergraduate degrees and the fraction of graduate degrees granted by the institution in the field in the year. Coefficients of the trend terms that resulted from these extended models appear in columns (b) of table 1.

A quick perusal of the table suggests that these coefficient estimates are very similar to those found in columns (a). On balance, we do not find strong evidence that the share of faculty positions going to the sciences at these Colleges of Arts and Sciences systematically increased over the twenty year period, even after one controls for changes in the distribution of majors at each college over time.

Table 2 presents finding similar to those in table 1 save that the dependent variable used in each case is the share of the faculty salary bill that goes to each of the three fields. It is possible that more resources may be going to sciences rather than to the humanities and the social sciences, even if the share of faculty positions going to the sciences has not increasing, if the salaries of scientists have been increasing relative to the other two disciplines over the twenty-year period.

\footnotetext{
${ }^{8}$ For example, at Cornell undergraduate students can receive degrees in biology from the College of Agriculture, as well as the College of Arts and Sciences.
} 
A quick perusal at table 2 indicates that there is no evidence to support this hypothesis. Very few of the trend coefficients in the science share equations are statistically significant and those that are tend to be negative rather than positive. On balance, these findings do not suggest that the share of these Colleges of Arts and Sciences faculty salary bills going to the sciences increased over the 20-year period. IV. Concluding Remarks.

Our findings that, on balance, faculty resources at the 15 colleges of arts and sciences located in selective private research have not been systematically reallocated to the sciences and away from the arts and humanities and the social sciences may seem surprising to some observers. However, to any college dean, who knows how difficult it is to reallocate positions even across departments within the same broad disciplinary area, they will not.

The institutions did not all experience similar rates of growth of total faculty size during the period. Total faculty size actually fell at 5 of the colleges in the sample; at several of these faculty size fell by more than 10 percent. In contrast, total faculty size at another 5 of the colleges grew during the period by roughly 10 to 20 percent. A reasonable conjecture is that it is easier for dean's to change the disciplinary composition of their colleges when total faculty size is growing than when it is contracting. If this conjecture were correct, one might expect to observe any shift of faculty lines towards the sciences occurring at the latter set of colleges. However, we do not observe this in our data. Hence our findings may simply reflect that administrators and faculty at these colleges have a strong sense of what a liberal arts education should consist and that this 
leads faculty allocations across broad subject matter areas to be roughly constant, on average, over time.

Our findings should not be interpreted as being the definitive word on whether the growth of science has crowded out other things at research universities. It may well be the case that the college of arts and sciences' shares of faculty positions at these universities has declined over time as the shares of other colleges, which are heavily science oriented, such as engineering and medicine, have increased. Put another way, it may be that the growth of science at the universities has constrained the growth of total faculty positions at their colleges of arts and sciences. This is not a conjecture that is straightforward to test because of the large number of faculty positions in these other colleges at some universities that are financed primarily by external research funding.

Similarly, the growth of science may have crowded out things other than faculty at these universities. For example, increased institutional provision of research assistants for the sciences may have led to a decreased availability of internal funds to support teaching assistants in the humanities and social sciences. Or increased institutional support for scientific research facilities and start-up costs for scientists may have reduced the funding that is available for travel and other "perks" in the humanities and social sciences. Finally, it may be that the cost of scientific research facilities caused institutions over the period to increasingly redirect their fund raising priorities towards raising funds for buildings, which has left them with a smaller share of funding for their current operations and for their endowments. ${ }^{9}$ If the latter has occurred, this may be reflected in tight budgets that have prevented the expansion of funding throughout the universities for

\footnotetext{
${ }^{9}$ In future work we hope to examine this question using data provided to us by the Council for Aid to Education.
} 
many endeavors, including raising faculty salaries. So research on the question that we posed in our paper's title has only begun.

\section{References}

Julianne Basinger, “A New Way of Classifying Colleges Elates Some and Perturbs Others”, Chronicle of Higher Education (August 11, 2000), A31.

Carnegie Foundation for the Advancement of Teaching, A Classification of Institutions of Higher Education: 1994 Edition (Princeton NJ, 1994)

Scott Jaschik, "Ivy League Agrees to End Collaboration on Financial Aid", Chronicle of Higher Education, May 29, 1991.

U.S News \& World Report, 1999 America s Best Colleges (Washington DC, 1999) 